\title{
ОЧЕРК ТЕОРИИ ТОГО, КТО ТАКОЙ БОГ, МАТРИЧНАЯ ЧАСТИЦА И КВАНТОВЫЕ ТЫЧИНКИ: В ОБРАЗОВАНИИ ВСЕГО И ВСЕЛЕННОЙ
}

\section{ТЕОРЕТИЧЕСКИЙ ТЕСТ}

SANTOS, Irineu de Oliveira ${ }^{1}$

SANTOS, Irineu de Oliveira. Очерк теории того, кто такой Бог, матричная частица и квантовые тычинки: в образовании всего и Вселенной. Revista Científica Multidisciplinar Núcleo do Conhecimento. Год 06, эд. 09, Vol. 02, с. 05-22. Сентябрь 2021 года. ISSN: 2448-0959, Ссылка доступа: https://www.nucleodoconhecimento.com.br/fisica-ru/кто-такой-бог, 10.32749/nucleodoconhecimento.com.br/ru/98379

\section{СВОДКА}

Учитывая, что Бог не является ничем абсолютным, единственным вечно присутствующим, неизменным и нейтральным элементом любого уравнения, который может содержать все, что мы можем понять как измерения, частицы, волны, материю, энергию, жизнь; там, где без этой силы Вселенная и обратное никогда не могли бы произойти, будучи одноручным, неоспоримым путем, это эссе направлено на то, чтобы разобраться с соображениями, связанными с частицей Бог, а также описать эту частицу, здесь крещенную как Матричная частица и Квантическая Эстамес (PM и EQ), о ее поведении в пространстве, что присуще пониманию его существования. Эта теория основана на собственных наблюдениях и библиографиях, уже опубликованных на основе исследований о понимании того, что такое великий Бог и полубоги или галактические боги, включая аналогию того, как вселенные содержат одобренного Бог и другие энергии меньшей силы, среди других исследований, связанных с темой,

\footnotetext{
${ }^{1}$ Физик-экспериментатор. Экономист.
}

$\mathrm{RC}: 98379$

Доступно в: https://www.nucleodoconhecimento.com.br/fisica-ru/кто-такой-бог 
которые касаются самой основной частицы, составляющей Вселенную, как в своей материи, так и в виде энергии и даже предсказывая существование антиматерии. Таким образом, для лучшего сжатия я описываю внутри этой более крупной структуры под названием «Бог», где есть фундаментальные частицы, состоящие из шести основных элементов, которые мы называем в этой функции «Квантовыми туманами», и энергетическую частицу со своим собственным светом, который мы называем «Матричной частицей», потому что это в основном свет Вселенной, где без этой лучистой энергии нет моторной жизни. что нас интересует. Тем не менее, в нескольких словах результаты показали, что если концепции формы и производительности PMeEQ будут широко изучены и поняты, эти данные позволят продвинуться вперед с точки зрения использования энергии, производства топлива и даже транспортировки материалов.

Ключевые слова: Бог, матричная частица, гравитационная, квантовая фризика, квантовые частицы.

\section{1. ВСТУПЛЕНИЕ}

Настоящая статья представляет собой сборник соображений и выводов, основанных на исследованиях и наблюдениях за тем, что такое Бог, теории струн и других исследованиях той же темы, которые касаются самых основных частиц, которые должны состоять из Вселенной и самой себя, а также дают пассивность классического и квантового фризического пространства, в качестве ключевого элемента. Поведение внутри Бог этих элементов, как в формировании материи как фрормы энергии, так и даже в предсказаниях существования антиматерии.

Чтобы описать Бог вне религиозного или фрилософского контекста и особенно частицу, названную авторски (для этой теории) как Матричная частица и Квантовые Стумины (PM и EQ), необходимо также читать лекции о его поведении в пространстве-времени, которое присуще пониманию его

RC: 98379

Доступно в: https://www.nucleodoconhecimento.com.br/fisica-ru/кто-такой-бог 
существования. Это крайне сложная тема, так как большая часть информации получена наблюдательным, теоретическим и математическим способом, а от существующих исследований и используемых сейчас требуется широкое понимание предмета и определенная степень дедуктивности. Как только концепции формы и производительности PMeEQ будут широко изучены и поняты, в нашей повседневной жизни эти данные позволят продвинуться с точки зрения генерации и использования энергий, с некоторыми предложениями, описанными ниже, а также фрормы производства топливной энергии, фрункционирование человеческого разума, корреляция с фрункционированием Вселенной и нашего тела, отношения с окружающей средой и ее фоормами, будь то волны или частоты, а также перенос материи и ускорение тел или управление их ускорением.

Частица Матрицы является клеем и перекрестком фундаментальных частиц и для нас самым важным. Он существует в союзе 6 упругих Эстамов, и когда они вместе, они освобождаются от фоновых стен Вселенной, которые создают энергии и пространственные материалы, различимые в нашей Вселенной. Этот клубок высвобождается из стен ультрауниверсального воздушного шара гравитационным вращательным движением, геоэлектропространственными эксдуминационными разрядами, присутствующими в стене фона, который составляет Вселенную, и выпуклостями пентадименционных энергий и других частот, равных или превышающих их, которые действуют как ультра терка, извлекая и распределяя куски этого квантового клубка, позволяя им возникать: энергия, масса, гравитация, притяжение, резонанс, темная материя и темная энергия, поляризованные или нет, движение и время, антигравитация, антиматерия.

RC: 98379

Доступно в: https://www.nucleodoconhecimento.com.br/fisica-ru/кто-такой-бог 


\section{1 КЛАССИФИКАЦИОННОЕ ВВЕДЕНИЕ И ТЕОРЕТИЧЕСКИЕ ссылкИ}

Бог: ничего абсолютного, все, матка, пространство для формирования материи, которая допускает частоты, волны и вибрации, холод, отсутствие света и движения, пространство, проницаемость, проводник.

Философрски Бог - это зал, где проходят балы встреч между Этьен Кляйн ${ }^{[2]}$, потрясения Хиггса ${ }^{[3]}$, пространством музыкальных нот Бетховена ${ }^{[4]}$, местом, где Макс Карл Эрнст Людвиг Планк[5] создал свою теорию, среди прочих. Бог также кратко описан Helinando Oliveira, профрессором «Univasf», где он является координатором Лаборатории импедантной спектроскопии и органических материалов (LEIMO), в своей теме «Бог и наука», однако мы не согласны в части этой презентации (OLIVEIRA, 2019). Бог пребывает в совершенстве нашей внутренней жизни, в отношении людей как живых, потому что, конечно, Бог также находится внутри нас, регенизируя наше расстояние и поддерживая нашу вибрацию и температуру, в то время как каждый вид волны пересекает нас, не причиняя вреда и не вызывая молекулярного уменьшения расстояния между нашей материей. Мы знаем, что вызывает любой пространственный дисбаланс между молекулами или даже между клетками, говоря о живых существах и их перспективах.

\section{2 ВВЕДЕНИЕ В КЛАССИФИКАЦИЮ И ТЕОРЕТИЧЕСКИЕ ссылки}

Матричная частица и квантовые тычинки (PMeEQ) - это частицы, которые создают и объединяют всю материю и энергию, существующие в нашем временном измерении, они распределены по Вселенной и составляют все, что существует. Матричная частица поддерживается и / или закрепляется в зависимости от ситуации шестью фундаментальными квантовыми тычинками / силами, которые могут иметь треугольную, квадратную или шестиугольную

RC: 98379

Доступно в: https://www.nucleodoconhecimento.com.br/fisica-ru/кто-такой-бог 
форму, и РМ имеет массу и размер 5 из этих квантовых тычинок, где шестая тычинка / Квантовая сила может изменяться по своему положению и времени / силе, будучи способной принадлежать частице «A» или частице «В», а также частице В, которая может делить струну с частицей «С». Это движение дикой квантовой тычинки отвечает за все движения во Вселенной, потому что его дестабилизация перемещает $\mathrm{PMeEQ}$, формирующие ффизические материалы и энергии, из классической и квантовой фризики, размерной, многомерной, пятимерной и пространственной. Но PMeEQ также являются барьерами и изолятором как для самих себя, так и для других сформированных и фрормирующихся частиц равного или большего размера, будь то классические квантовые или даже размерные.

Эти формы энергии/волны и материи, присутствующие в гравитационной оболочке макровселенной, являются нейтральной структурой, как якорные, и остаются нейтральными до тех пор, пока не подвергнуты воздействию естественной принудительной спиральной гравитационной силы Вселенной или не будут вызваны приближением другой размерной вселенной. Для $\mathrm{PMeEQ}$ не редкость или необычность иметь форму цветка, одуванчика, добавляя больше эстаменов, потому что в квантовом мире выше может быть дно, а снаружи может быть внутри, и связи могут быть вместе, но разделены, в настоящее время, но в то же время в будущем или в прошлом, может случиться так, что квантовые тумеры находятся в скэйне, приобретая другие свойства и характеристики, невообразимые в это время.

Это еще более важно, когда диагностируется, что эти частицы являются активными и способными к памяти материалами (CHVYKOV et. al. 2021), они являются временными, проходящими в трех временных стадиях классической фризики и многомерных временах, и могут давать пентадименционаи / экзадименсиональные, классические или квантовые скачки.

RC: 98379

Доступно в: https://www.nucleodoconhecimento.com.br/fisica-ru/кто-такой-бог 
В рамках классической ффизики, говоря о частицах и пространстве, связи диктуют нашу жизнь от вечности, говоря по аналогии, облака поддерживаются только размерностью молекул, которые поддерживают союз и расстояние между ними, это почти без гравитации, хотя и страдает эффектом Казимира[6]

\section{2. РАЗВИТИЕ И ПРОИСХОЖДЕНИЕ}

Говоря об интерактивных свойствах и возможностях Бог, в научном смысле, кажется, нет практического смысла в нашей нынешней степени развития, но он есть, и Бог в основном находится и признается как автор / соавтор / главный директор, поскольку это проясняется как место, где все всегда происходит, более продуктивно.

Не поддерживая избыточность очевидного, это теоретическое эссе будет описано из данных, собранных в других исследованиях, наблюдениях и других теориях, и во многом по моему собственному пониманию, сосредоточив внимание на начале связей и движений.

Феномен освобождения и дезагрегации частиц Матрицы и квантовых оглушений внутри квантового клубка происходит в основном из фоновой стены Вселенной различными явлениями, из которых Бог участвует, и там начинается сага, в сумме PMeEQ с другими PM, и высвобождение 6 гравитационных квантовых эстамов, где «возможно» - это тау, электрон, мун, граф, X и «С» (джокер), или, что более вероятно, что-то меньшее и с другими характеристиками, кроме кванта, которых наш разум и понимание не достигают.

Следует отметить, что эти Квантико Ститы не являются струнами Теодор Калуца или Калуцы Клейна[7], что вменило им другое значение в значении швартовки и дистанцирования массы в их сумме, полярности, формирователей жидкостной гравитации, смазочных материалов и главным образом движения.

RC: 98379

Доступно в: https://www.nucleodoconhecimento.com.br/fisica-ru/кто-такой-бог 
Принцип агрегаций и дезагрегаций происходит от поляризованного вращательного гравитационного спирального сжатия, когда один PMeEQ пропитывает другой и сосуществование распадается и освобождает РМ от ограничительной геометрии квантовых пней, оставляя свободными частицы и пни, они приобретают другие характеристики и свойства, а также под влиянием гравитационной сингулярности и при определенных скоростных условиях, время, пространство, длительность и волнение приобретают полярность и могут трансформироваться в энергию, волновую материю и время, даже все в одном и том же пространстве/времени.

Когда и где начинают происходить сингулярности, это разделение и реорганизация РМ, поддерживающих квантовых тычинок. РМ могут стать материей или энергией, а квантовые тычинки - темной материей или темной энергией (см. Прилагаемый рисунок). Изначальная квантовая запутанность, сформировавшая задние стенки макро Вселенной, возникла в незапамятные времена объединением и трением многомерных энергий нескольких сверхвселенных, носителей миллиардов галактик, скоплений, которые остановили движение трения, «затвердели» это. вращающаяся энергия, которую я называю матричным спиральным запутыванием РМ и его квантовых тычинок.

Узнаваемая масштабная модель, которую мы знаем, и больше похожа на то, что мы должны сравнивать с энергией или нейтральностью, как представляет РМ- это статическое электричество. Используя аналогию снова, хорошим примером является шерстяная швабра, проезжающая над автомобилем и электростатически заряжаемая при получении груза материи, которая находилась там в состоянии покоя.

\section{1 ВЫСВОБОЖДЕНИЕ ЧАСТИЦ}

PMeEQ были распределены по всей Вселенной, начиная с выхода материи из задних стен Вселенной (Теория сознательных творений). Вселенная имеет

RC: 98379

Доступно в: https://www.nucleodoconhecimento.com.br/fisica-ru/кто-такой-бог 
форму пузыря в бутонах, не совсем круглой фрормы. Самая реальная возможная аналогия состоит в том, что Макро-Вселенная, состоящая из миллионов кластеров, похожа на более округлый желудок, с большим количеством стенок, чем у обычного человеческого желудка, но с входом и выходом только как у людей, только с более луковично-подобными слоями, где невидимые измерения плавают или, точнее, на других частотах за пределами наших показаний с помощью текущего оборудования, или наблюдаются, просто глядя, плавая в существовании, непостижимом для нашего ограниченного современного сознания, В этих измерениях , Я понимаю, что действуют силы, которые нам неизвестны, где в материальной плоскости, скажем так, ощутимо, энергетический материал выделяется из стенок при вращении воздушного шара (желудка), потому что есть несовершенства, удары, удары, гравитационные толчки и притяжение от поляризованной оси Вселенной, из которой высвобождается материал, заполняющий пространство. Сплетения освобождаются от стен макро-вселенной, в основном из-за неправильного кругового вращательного движения, и достигают центра вселенной, как галактики, где река горизонтальной энергии циркулирует от полюса к полюсу, образованного матричными частицами и тычинками. Кванты уже возбуждены в движении, где новые заряды с началом сжатия космических газов создают солнца и поляризуют их. Эти танцующие поляризации создают планеты из остатков газа, которые солнца не использовали, и полосатую форму почти всех галактик, а также рассеивают PM, которые освещают Вселенную, и EQ, которые, кажется, создают темную, но едва проницаемую завесу. Присутствует вибрация. .

Двумерным примером может быть вихрь воды внутри яйцевидного воздушного шара, где плавают очень тонкие, многослойные сети и где каждый переход или узел этой сети будет галактикой РМ и квантовых пней.

Частью $\mathrm{PMeEQ}$ являются преобразованные и созданные материи, и их присутствие в определенных промежутках и случаях времени, подчиняющихся

RC: 98379

Доступно в: https://www.nucleodoconhecimento.com.br/fisica-ru/кто-такой-бог 
космическому влиянию, обращает вспять вращение и полярность, как движение косяка испуганных сардин, или, по другой аналогии, другим примером, был бы человеческий желудок или свинья, пересеченная электрическим проводом, толстый, голый, то, что время тянет время, передает энергию. Эти инверсии происходят мгновенно в космическом времени, управляемом целыми стенами Вселенной или галактик, где они не зависят от того, сколько триллионов световых лет она импортирует.

Это происходит в нашем подсчете времени, который может быть равен нулю, «времени», так что эти инверсии и смещения происходят, хотя в затронутом вопросе может потребоваться большее пространство времени, чтобы произойти, нашим восприятием того, что является слишком большим или слишком маленьким временем, или быть секторальным явлением, космологически говоря.

Частица Матрицы является фундаментальным нематериальным элементом, который при срабатывании действует как реактор или что-то пропитанное статическим электричеством, может быть твердой или жидкой гравитацией, может быть волной, действующей с Стаутами, или даже антиматерией, частицей, которая окружает и сопровождает все другие существующие незначительные частицы. Эти частицы при возбуждении при определенной гравитационной силе, скорости и пространстве времени могут образовывать нематериальный энергетический хвост, подобно квантовой комете, независимо от количества материи, которая ее сопровождает, служит материальной истиной для всех частиц, даже если она также существует внутри этой же частицы, составляющей материю. РМ не притягиваются в первичной стадии, либо ограничивая крепление $\mathrm{EQ}$, либо потому, что у них нет предпочтений или аромата, хотя они всегда вместе и могут действовать как реле, но могут приобретать поляризацию и допускать существование энергии своими движениями, они имеют память о значении и движении все еще в творческой

RC: 98379

Доступно в: https://www.nucleodoconhecimento.com.br/fisica-ru/кто-такой-бог 
нематериальности, и передает это движение, когда они приобретают массу и создают энергию.

Каждое измеримое пространство в наименьшем квантово существующем измерении является Матричной частицей с еe квантовыми стумбами. Пространство галактик - это материя и антиматерия, когда они заряжены энергией квантовых частиц. Матричная частица и квантовые колья, высвобождают, притягивают и создают всю существующую или отсутствующую энергию во Вселенной, это то, что определяют ученые, темная материя и энергия и вся существующая материя, она сосуществует между двумя полярностями, различными измерениями и гравитациями, потому что она нейтральна, пока не достигнет определенной инерции скорости, пространства и времени. Она статична до тех пор, пока некоторая сила вращения не возбуждает, само вращательное движение галактик существует под влиянием образования, которое его агрегировало, и которое поддерживает движение галактик, солнц, планет и звезд любой величины в потоке и рефлюксе.

Ультравселенная овоидной фрормы пересекается гравитационной осью классической энергетической материи, а также пяти- или шестимерными силами, вращающимися в форме нескольких переплетенных спиралей ДНК. Эта ось представляет собой материальный образец связей между релятивистскими и квантовыми теориями, присутствующими в твердых небесных телах (Теория эфира как элемента).

Если бы частица Матрицы и ее квантовые стумены не перемещались при определенных условиях, фроновые стены также перестали бы изгонять частицы, а собственное вращение стен замедлилось бы, разрушая систему. Во всех ситуациях матричная частица и ее квантовые состояния должны быть частью расчета, например, хвост и мантия перед ускоренным протоном в HCL, а также когда статические инерциальные нагрузки, умноженные в конце маршрута, делятся. Всегда эта частица, размером с «квант» или меньше, течет как

RC: 98379

Доступно в: https://www.nucleodoconhecimento.com.br/fisica-ru/кто-такой-бог 
ультраквантовая и гравитационная жидкость, чтобы взаимодействовать с фризическими явлениями материи и с энергиями различных размеров и частот.

Теория РМ в некоторых отношениях согласуется с теорией Калуцы-Клейна о большом количестве измерений и о том, что в большинстве случаев квантовые состояния закрыты на своих концах. Они также согласны с тем, что Матричная частица находится в любой из своих бесконечных мод вибрации или нейтральности и может принадлежать к любому виду, существованию, частоте, цвету или аромату, который даже составляет человека, когда человек видит биофотоны, которые мы называем и фотографируем как ауру.

\section{3. ЗАКЛЮЧЕНИЕ}

Зачем идентифицировать Бог и называть другие элементы частицами Матрицы и Квантовыми Остублями (PMeEQ). Во-первых, потому что мы должны объяснить существование пересечения галактик, больших отрицательных и положительных центров тяжести, которые принимают и репонирует материю в нашем сверхмерном космосе, и почему мы называем ее черными дырами, а также функционирование магического квантового расстояния и его гравитационных фрорм, которые действуют в нашем собственном существовании и как оно есть везде (в том числе и внутри нас, где - энергия известна как свободная воля и фрлуктуации пространства). Это перемирие толчков между протонами, нейтронами вокруг молекул в триллионах комбинаций нуждается в пространстве, потому что эта опорная структура взаимодействий - жизнь, но она нейтральна, как и наши действия и движения, где мы определяем и определяем все, будущее и пути.

Bсе, что происходит от существования этой изначальной силы Бог, и из этих РМ и EQ они являются материей, частотой, измерением, является смыслом движений и агрегирующей гравитации, фрермой и клеем клубка, оно поддерживает баланс между притяжением и дистанцированием, обеспечивая гармоничное существование и формы энергии, и связь между всеми

RC: 98379

Доступно в: https://www.nucleodoconhecimento.com.br/fisica-ru/кто-такой-бог 
существующими вещами, включая многомерные, переменные и интеллектуальные частоты.

Во многом мы согласны с Теорией фрункционального удобства Júnior (2019) и Ровелли (2017), где делается вывод, что мы создаем реальность из создания мысли о том, что реально быть реальностью, которая затем порождает реальность. Аномалия изменения воды по мере того, как мы наблюдаем, прикасаемся к ней и справляемся с ней, является величайшим доказательством нашего участия во всей Вселенной и нашего вмешательства во все простыми наблюдениями и мыслями. Если мы изменим этот материал, этот звездный элемент Н2О, простым актом взятия его в руки и взятия в рот, вмешиваясь во всю структуру нашего тела, фризическую и химическую, чего может достичь наш ум? Можем ли мы фрормировать будущую реальность мыслью в агрегации этих матричных частиц? Будущее уже проецируется мыслью вчерашнего дня, и то, что мы найдем в поглотителях пространства, это то, что создало наше воображение, или это то, что мы подсознательно знали при формировании фундаментальных творческих энергий?

И почему это исследование в практическом, непосредственном фуннциональном аспекте? Потому что для того, чтобы разорвать гравитационные связи, развить неисчерпаемые источники энергии, внести смысл в потребление планетарных богатств, особенно в этот момент развития, и оправдать наше существование, наряду с продвижением коммуникаций и новых центров управления и контроля, мы должны обратить внимание на то, чтобы не быть устраненными «ИИ» искусственным/механическим интеллектом (OLIVEIRA, 2019). Последние математические данные изучения принятого пути, указывают на неконтроль нашего творения, ввиду тревожных данных разрушения, которые мы реализуем каждый новый день, мы должны доказать, что мы потомки универсальной цепи событий и что мы признаем этих существ от Бог и вопросов изучения Теории выше нас. Мы должны уважать их, ибо они, наши разрешения, мы прощены. Он «Бог» - это то, чему даже правительства

RC: 98379

Доступно в: https://www.nucleodoconhecimento.com.br/fisica-ru/кто-такой-бог 
подчиняются, приписывают ценность и уважают спонтанно, даже принимая в своих монетах и символах его имя «БОГ», давая понять (например), что только он может судить.

Последними экспериментами с «ИИ», не давая существования этой божественности, мы остаемся для того, чтобы нас судили по логике, которая не может распознать наши ошибки, не устраняя нас тем, что мы делаем и практикуем. Мы должны знать, что составляет наши ограничения, где находятся наши барьеры, и искать новые пути и другие логические планы. Без логического плана ограничения для «ИИ», помимо 4 законов Иссака Азимова, которые могут показаться нелогичными для «ИИ», перед лицом разрушения мира мы незащищены, поэтому мы должны предсказать, что вся свобода, которую мы переносим машинам сегодня, имеет ограничения в собственной неспособности не иметь возможности относиться к этой силе большего «Бог», например.

А кто такой Бог вне богословских догматов? Кто может быть у Бог, холодно изучающий известные частоты и проецируемый как творческая сила для фрормирования и агрегации материи? Какой может быть интерес к чему-то столь же могущественному в крошечных существах, как мы, например? В чем может быть причина нашего существования для такого существа или таких существ? Ионная энергия, которая кажется малой даже у миллиардов людей, и даже в меньшей степени других живых существ, и, возможно, сама гравитация, являются универсальным планом поддержания заземления для высвобождения биоклеточной энергии, являются не исключенными возможностями для оправдания нашего измерения, поскольку мы уже доказали существование других с другими законами фризики.

Тогда мы можем сделать вывод, что существует высший Бог (предположим, что он полноценный человек, и что у него есть мозг, который контролирует все) и внутри него несколько вселенных, каждая со своими собственными

RC: 98379

Доступно в: https://www.nucleodoconhecimento.com.br/fisica-ru/кто-такой-бог 
центральными нейронами, чтобы командовать и общаться с Богом-отцом. В центре его желудок, который вставляет в отца все энергии самых разнообразных фрорматов, преобразует их и перенаправляет в другие измерения. В этом огромном комплексе есть элемент, которым является наша планета. Рассматриваемые как энергия, мы не являемся материей для этого существа, но, возможно, мы являемся материей для группы ближайших энергетических нейронов, которые были бы нашими личными богами, теми, кто смотрит на нас как на пищу, кто вмешивается в наше развитие прожорливостью, существами, живущими в невообразимых временных пространствах, с вневременными планами размножения, как некоторые боги для каждого кластера. то есть для каждого слоя желудка или для каждого измерения. Все желающие быть более мощными или репрезентативными нейронами перед телом БОГ, а некоторые в зависимости от наших биоионных плавающих энергий, которые являются временем положительным, отрицательным временем. Когда они хороши, они питают позитивных существ, а если отрицательных, темных существ. Дело в том, что мы все плоды преобразований, энергии в узкомерном движении. Наше существование само по себе является актом насилия, мы являемся потребителями материи, это вредит Вселенной, потому что мы вынуживаем дисбаланс в нашем собственном существовании. Мысли и вибрации являются негативными фракторами, хотя и частью более широкого плана этих вневременных разумов, для которых наши экзистенциальные вопросы неуместны и нелогичны, поскольку мы находимся внутри системы и существуем с определенной целью.

Меньшие Боги, которые не используются в качестве материального ориентира в этой Теории, являются индикаторами и маркерами, которые вмешиваются в самые примитивные формы биоактивных освободителей энергии (мы), всасывают и питают всю цепочку. Также кажется, что по мере того, как время и эволюция этих видов суперсуществой эволюционирует и перемещается на другой план или измерение, существа здесь также изменяются и создают

RC: 98379

Доступно в: https://www.nucleodoconhecimento.com.br/fisica-ru/кто-такой-бог 
новые образы поклонения, а также новые храмы поклонения, направляя и модулируя другой тип высвобождения энергии.

В дополнение к человеческим логистическим вопросам интеграции с «ИИ», мы должны думать о новых $и$ беспрецедентных средствах действия и исследования нашей планеты, о новых средствах передвижения, создании физических пространств земель, которые теперь недоступны или дороги, если их возвести материальными фризическими барьерами, такими как морское дно и небо, например, (пространство между почвой и стратосферой), это не существует по нашей степени развития и возможности создания таких сил, как стены отталкивающих энергий гравитации, без необходимости действовать материально, тратя другие энергии.

Эта теория может по-другому, зная строение первичной материи, скрыть от гравитационного притяжения части материи, которые мы не хотим терпеть внешние воздействия, найдя правильную конфигурацию $\mathrm{PMeEQ}$, который создает притяжение, и я оставляю в открытом доступе, что мы можем создать темнеющий пузырь вокруг объекта, который мы хотим, даже используя фотоны, чтобы гравитация не чувствовала его, например, стенки цеппелина вокруг объекта, так что в своей жидкости образуют PMeEQ так, что они не могут впитывать и удерживать пропитанный объект, представляющий интерес для высвобождения веса и/ или массового распознавания, или энергии и частоты, которые отражают притяжение $\mathrm{PMeEQ}$ в его мельчайших фрормах, где он пропитан, таким образом, гравитация не находит ничего, что можно было бы связать или привлечь. Мы должны работать над тем, чтобы водонепроницаемость объектов от этой жидкой энергии, которая является гравитацией.

Эта сингулярность сокрытия от первичных сил, вещей, людей или областей материи также является объектом этого исследования, способ путешествия в гравитации без нарушений, возникающих в гравитации, как скальпель в

RC: 98379

Доступно в: https://www.nucleodoconhecimento.com.br/fisica-ru/кто-такой-бог 
желатиновом отверстии и закрытии без следа является целью, наряду с тормозом уважения к более крупной сущности для «ИИ».

Предполагается, что в пределах некоторой частоты, размерности или длины волны электростатического или непрерывного света, найденная жидкость в квантовой инженерии, на ее различных длинах волн или аналогичная на еще более высоких скоростях, является ключом к преодолению притяжения и выгодной переориентации этой силы.

Новые технологии, в том числе «ИИ», нуждаются в фриксированной отправной точке, которая дает им безопасность, так же, как мы, люди, также чувствуем эту потребность как наличие неба и твердого объекта, на который можно положиться, и именно отсюда исходит Бог, давая нам эту прочность, потому что для того, чтобы было пространство гибкости или текучести, необходимо пространство. Только пространство во всех его фрормах и измерениях избегает перегрева, который является разрушительным, хотя и созидательным, во всех измерениях, особенно в третьем и четвертом, где мы живем и создаем наши машины. Без расстояний, времени и пространства ничего не останется, если наши новые электромобили не имеют охлаждения в батареях, чтобы избежать слишком большого трения, не служат, как и квантовые/органические компьютеры или нет. Эти холодильные установки требуют пространства, это должно быть принято на функциональную сторону в интегральности мысли новых мыслящих машин, и это пространство должно пониматься как якорь, который поддерживает и допускает функциональность взаимодействий. Наш Бог и наша проницательность составляют пространство и по нему изначально составляются, и оно должно быть привито в вычислениях как нечто живое.

Бог - это матка, центральная ось Вселенной - пуповина, матричная частица - яйцеклетка, пятна - сперма, и целое - это наша интерпретация того, как мы видим жизнь и творение.

RC: 98379

Доступно в: https://www.nucleodoconhecimento.com.br/fisica-ru/кто-такой-бог 
В соответствии с вышесказанным, Д-р проф. Elcio Abdalla (2004) подтверждает теорию, представленную в этой работе, поскольку она содержит лицо призмы и взгляд на множественные измерения, принося соответствующие аспекты, но с другим чтением, интерпретацией и пространственными, фризическими и фрилософрскими результатами.

Наконец, мы достигли точки, когда наука и философия входят в атавистические заботы о человеке, которые больше не являются практическими, техническими и полезными, постулируемыми фризикой и осуществляемыми технологией, и становятся все более техническими и спекулятивными.

Поначалу можно сказать, что происхождение и структура геометрии пространства-времени до сих пор неизвестны. Согласно современной науке, квантовая геометрия имеет квантовые операторы, представляющие пространство, и его интерпретация, ранее считавшаяся простой, стала более сложной. Более того, в рамках квантовой гравитации, в черных дырах и при очень высоких температурах важно учитывать все частицы и взаимодействия, генерируемые бесконечно, согласно теориям струн. По сути, они все еще могут влиять на дополнительные измерения теорий струн и других теорий М, еще больше повышая сложность проблемы. Некоторые считают, что дополнительные измерения уже близки к наблюдениям. В связи с этим с этими измерениями начали заниматься общие квантованные теории поля, и старая идея Калуцы и Клейна, введенная в 1920-х годах, стала частью почти повседневной идеи, где другие измерения стали повсеместными. (ABDALLA, 2004).

Мы сейчас находимся в гораздо более спекулятивной зоне, где объект исследования уже не связан только с исследованием и начинает выходить за пределы того же самого не только потому, что он является чем-то гораздо большим, как и наша Вселенная, но и потому, что в нем содержится исследователь, так что последний не в состоянии наблюдать за своим

RC: 98379

Доступно в: https://www.nucleodoconhecimento.com.br/fisica-ru/кто-такой-бог 
объектом изучения. поскольку нет причинно-следственной связи между одной вселенной и другой. Это квантовая модель, наблюдаемая в новом измерении, в котором мера, фрундаментальная для самой интерпретации теории, невозможна. Он раскрывает новые теоретические построения, основанные на теории струн, с новыми пространственными измерениями, с трансцендентным временем, а также с множественными творениями вселенных (ABDALLA, 2004).

Уже какой профресcop доктор João E. Steiner (2006) и другие фризики и ученые ставят, дает диффреренциацию этого способа интернализации Вселенной и ее фрормирования. Хотя они точно помещают то, что обсуждается сегодня и что, в частности, имеет тот же вес, что и плоская Земля и гелиоцентрическая или галактоцентрическая, эти наблюдения, исследования и результаты категорически расходятся и противоречат другим исследованиям, в том числе и теории Большого взрыва, поскольку для того, чтобы это явление действительно произошло, мегавселенная не могла бы иметь центральную ось энергии.

На протяжении всей истории было кратко представлено несколько космологических моделей. Таким образом, эволюцию идей можно понять по последовательности моделей, таких как теория плоской Земли, геоцентрическая модель, гелиоцентрическая и галактоцентрическая. (STEINER, 2006)

За последние сто лет ученые разработали теорию, которая способна описать самые сложные наблюдения, которые в настоящее время проводятся, и которая показывает происхождение Вселенной в соответствии с моделью, которая может быть исследована с научной точки зрения, это теория Большого взрыва. Недавно эта теория была улучшена до новой концепции, а именно инфляционной Большого взрыва. Открытия, сделанные на рубеже тысячелетий, показали, что все знания, которые мы имеем сегодня, являются лишь верхушкой айсберга, присутствующего во Вселенной, захваченной

RC: 98379

Доступно в: https://www.nucleodoconhecimento.com.br/fisica-ru/кто-такой-бог 
энергией и темной материей, природа которой до сих пор неизвестна (STEINER, 2006).

Излагая приведенные выше взгляды на то, как физические законы якобы через взгляд людей мыслят и ведут себя перед лицом необъяснимого и математической/фризической/религиозной вселенной, ожидается, что появятся новые пути к подходам без моральных, реалистических резервов.

\section{ПРЕДЛОЖЕНИЕ}

Путь и направление, я думаю, теперь открыты, у нас будет интеллект и сила мысли с отношениями. Я думаю, что это мост, который отсутствовал при пересечении/пересечении, чтобы объединить теории, преодолеть барьеры и сломать пустые убеждения различий, это все только наука, религия - это материальность, а обратное также верно. Последние исследования показывают, что мысль фрормирует нашу реальность (Jaime Marrone Jr/Карло Ровелли), и из реальности мы создаем будущее.

Зная, что Бог есть материя и неотъемлемая часть нашей повседневной жизни, исследований и экспериментов, я думаю, что можно будет иметь гравитационную силу ITAIPU в пространстве наконечника карандаша, создавать материальные энергетические корабли переменной фрормы и ускоряющихся движений, которые выходят за пределы времени, создавать новые неисчерпаемые источники энергии, такие как те, которые доступны в черных дырах, там, где существуют «N» числа матричных частиц и квантовых эстаменов, существуют новые формы многомерных материалов и энергий.

В рамках теории предложения могут быть почти бесконечными, но мы всегда сосредотачиваемся на двух основных предложениях о срочности момента, когда планета проходит, и где мы можем сотрудничать, а именно: 1-я инкапсуляция объектов или вещей в сетях затемнения / сокрытия гравитации и 2-я климат-контроль путем притяжения или отталкивания подвешенных

RC: 98379

Доступно в: https://www.nucleodoconhecimento.com.br/fisica-ru/кто-такой-бог 
воздушных океанов, две реальности, которые могут быть реализованы сегодня, с небольшим риском (жадность человека).

\section{ИСПОЛЬЗОВАННАЯ ЛИТЕРАТУРА}

ABDALLA, E. A estrutura do universo, a mecânica quântica e a cosmologia moderna. Revista USP - São Paulo, n. 62, p. 6-29, junho/agosto 2004.

CHVYKOV, P. et. al. Low rattling: A predictive principle for self-organization in active collectives. Revista: Science Vol.: 371, Issue 6524, pp. 90-95. 2021.

JÚNIOR, J. M. Teoria da Conveniência Funcional: Uma reflexão sobre as propriedades fundamentais da matéria. Revista Científica Multidisciplinar Núcleo do Conhecimento. Ano 04, Ed. 07, Vol. 12, pp. 133-157. Julho de 2019. ISSN: 24480959

ROVELLI, C. A realidade não é o que parece: A estrutura elementar das coisas. 1 Ed, Rio de Janeiro: Objetiva, 2017.

OLIVEIRA, H. Deus e a Ciência. Ciência nordestina, 2019.

SANTOS, I. de O. Teoria do Éter como elemento. 12/10/2003 Arquivo Nacional, não publicado, reg. 276.887. Livro 499. Folha 47.

SANTOS, I. de O. Teorias da criação conscientes. 30/07/1998 Arquivo Nacional, não publicado, reg. 156.719. Livro 258. Folha 343.

STEINER, J. E. A origem do universo. Estud. av. vol. 20 n. 58. São Paulo, 2006. Disponível em: https://doi.org/10.1590/S0103-40142006000300022

RC: 98379

Доступно в: https://www.nucleodoconhecimento.com.br/fisica-ru/кто-такой-бог 


\section{ВЛОЖЕНИЕ}

Просто иллюстративный авторский рисунок, где Бог - пустота, а точки - РМ, стержни - Квантовые Тычинки, но рисунок также мог быть треугольным или шестиугольным.

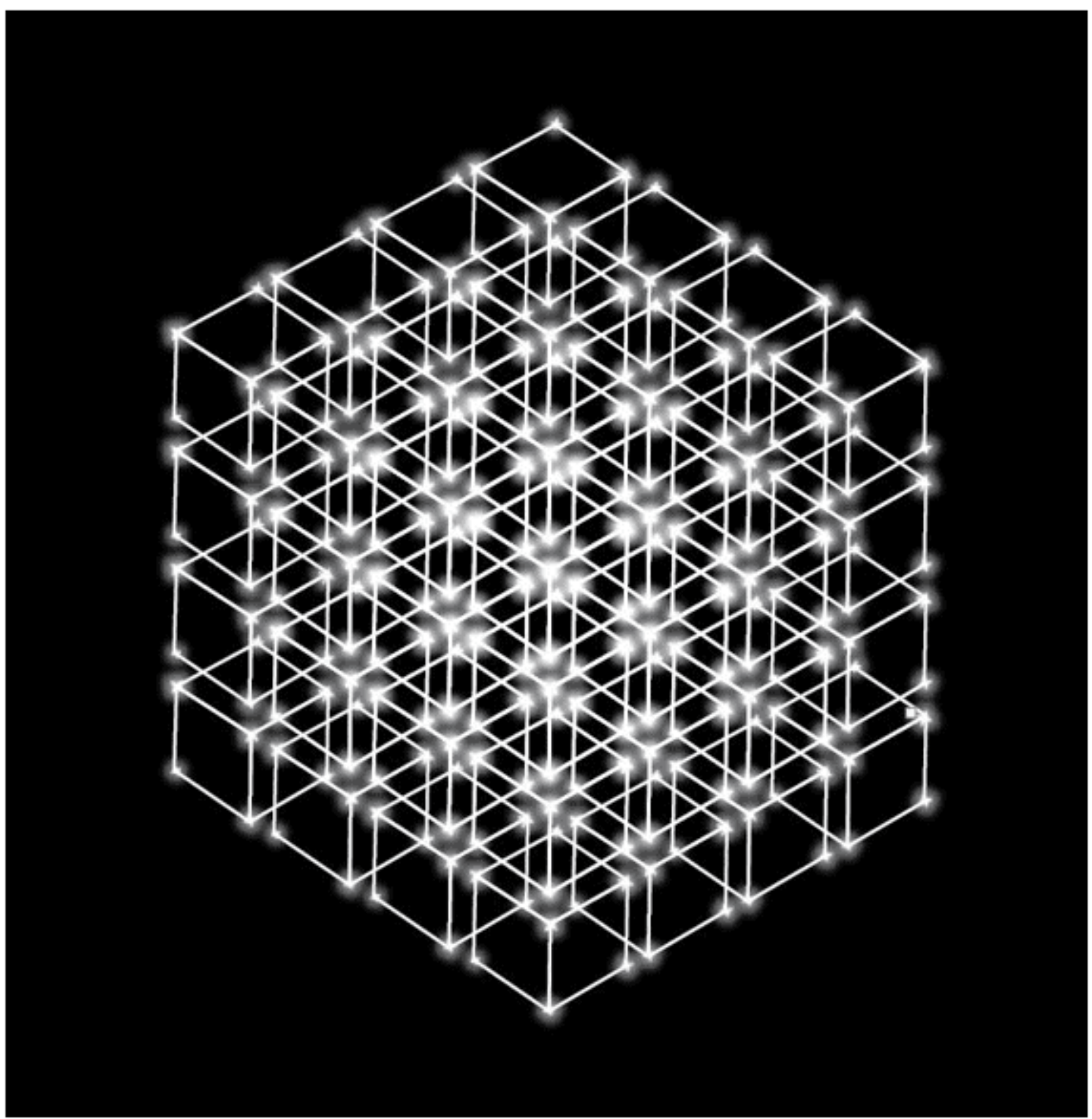

Оптическое изображение Бог, матричных частиц и квантовых тычинок. Когда PM находится в состоянии покоя в углах $E Q$, показывая расстояние,

RC: 98379

Доступно в: https://www.nucleodoconhecimento.com.br/fisica-ru/кто-такой-бог 
проницаемость и нейтральность до гравитационного возбуждения, когда РМ со своей собственной энергией и лучистой вибрацией, сложенной вместе, сорормирует массу и энергию, а тычинки сформируют массу, темная материя и темная энергия.

\section{ПРИЛОЖЕНИЕ - СПРАВОЧНАЯ СНОСКА}

2. Этьен Кляйн, фризик/философ Ph.D. École Centrale Университет, родился 01.04.1958. В своей книге «Время, которое проходит», фризик утверждает, что будущее уже существует, но мы можем его фрормировать.

3. Питер Уэр Хиггс, родился 29.05.1929, фризик-теоретик Эдинбургского университета, Лауреат Нобелевской премии по физике, по - Частица Бог хотя и не дал этого названия, был его редактором, также известным как «сущностная частица», бозон ХИГГСА теоретически рассматривается как материя Вселенной.

4. Людвиг Ван Бетховен, гений, немецкий композитор периода транскрипции между классикой и романтизмом рождение: 12/1770 Бонн, Германия смерть:26/03/1827 Вена, Австрия.

5. Макс Карл Эрнст Людвиг Планк, немецкий фризик, лауреат Нобелевской премии по фризике 1918 года. Квантовая теория, квантовая фризика, закон Планка.

6. Теодор Франц Эдуард Калуза, голландский фризик, (с 15/07/1909 по 04/05/2000) подчеркнул исследование «Эффрект Казимира», Лейденский университет - Две сверхпроводниковые жидкости.

7. Теодор Ф.Е.Немецко-польский математик Калуца (1885/1945), в 1919 году теоретизирует квантовую гравитацию в петле, что помимо 3 измерений существует четвертое, в очень малом круге, а в 1926 году математик Оскар Клейн (1894/1977) предложил 5-е измерение, которое можно было бы

RC: 98379

Доступно в: https://www.nucleodoconhecimento.com.br/fisica-ru/кто-такой-бог 
расширить или свернуть, сложить на себе, сложенный лист, прыгающий из одной точки в другую.

Представлено: Февраль 2021.

Утвержден: Сентябрь 2021 года.

RC: 98379

Доступно в: https://www.nucleodoconhecimento.com.br/fisica-ru/кто-такой-бог 